\title{
IUFOST2006/1389 \\ A Food Systems Approach to Understanding Food Security
}

\author{
P. Ericksen \\ GECAFS International Project Office;, NERC - Centre for Ecology, OX10 8BB, Wallingford, United \\ Kingdom \\ pjer@ceh.ac.uk
}

\begin{abstract}
Broadly described, food systems encompass all activities from production through to consumption, along with other key determinants of food security. Food security encompasses components of availability, access and utilization. The rapid rate of change in food systems across the world is resulting in highly variable and dynamic situations whose impacts and outcomes are uncertain. Evaluating the consequences of global environmental, economic, social and political change for food security requires a comprehensive, integrated and systematic approach. The holistic framework presented in this paper combines analytic tools from several disciplines to understand how the organization and interactions within food systems produce certain food security outcomes. It also considers the feedbacks produced within and by a food system that have future consequences for a range of socio-economic and environmental outcomes, and hence, future food security
\end{abstract}

